\title{
Cellular Responses to Auxin: Division versus Expansion
}

\author{
Catherine Perrot-Rechenmann \\ Institut des Sciences du Végétal, UPR2355 CNRS, 1 Avenue de la Terrasse, 91198 Gif sur Yvette, \\ Cedex, France \\ Correspondence: catherine.rechenmann@isv.cnrs-gif.fr
}

\begin{abstract}
The phytohormone auxin is a major regulator of plant growth and development. Many aspects of these processes depend on the multiple controls exerted by auxin on cell division and cell expansion. The detailed mechanisms by which auxin controls these essential cellular responses are still poorly understood, despite recent progress in the identification of auxin receptors and components of auxin signaling pathways. The purpose of this review is to provide an overview of the present knowledge of the molecular mechanisms involved in the auxin control of cell division and cell expansion. In both cases, the involvement of at least two signaling pathways and of multiple targets of auxin action reflects the complexity of the subtle regulation of auxin-mediated cellular responses. In addition, it offers the necessary flexibility for generating differential responses within a given cell depending on its developmental context.
\end{abstract}

$P^{1}$

ant growth and development are controlled by the action of plant hormones among which auxin has been implicated in virtually every aspect. These two processes are sustained by coordinated cellular behaviors, basically cell division, cell expansion, and cell differentiation. Plant growth corresponds to the increase in size of pre-existing or newly formed organs and results largely from cell enlargement, also referred as cell expansion or cell elongation (anisotropic expansion). The first evidence of a "transported messenger" promoting cell expansion has preceded the biochemical discovery of the auxin molecule per se, through a series of historical experiments on tropisms starting with the observation of grass coleoptile bending in response to light by Charles and Francis Darwin. Plant development is a continuous process beginning during embryogenesis with the formation of the primary plant body (embryonic root and embryonic shoot) and continuing postembryonically with the regular production of new organs (roots, leaves, branches, and flowers) through de novo initiation from pools of stem cells. Organogenesis requires the controlled production of new cells within specialized zones named meristems. Auxin promotes cell division and meristem maintenance and also plays an important role in the establishment of cellular patterning. Plant development

Editors: Mark Estelle, Dolf Weijers, Karin Ljung, and Ottoline Leyser

Additional Perspectives on Auxin Signaling available at www.cshperspectives.org

Copyright (C) 2010 Cold Spring Harbor Laboratory Press; all rights reserved; doi: 10.1101/cshperspect.a001446

Cite this article as Cold Spring Harb Perspect Biol 2010;2:a001446 


\section{Perrot-Rechenmann}

thus integrates the regulation of cell proliferation and growth with further cell expansion and differentiation. The distinction is made here between cell growth and cell expansion as they correspond to distinct processes. Cell growth refers to the increase in size of proliferating cells, is part of the cell cycle and coincides with an increase in total nucleic acid and protein content and no vacuolization. In contrast, expansion of the cell is often associated with endoreplication, is concomitant with vacuolization, and leads to differentiation (Fig. 1).

Auxin is a major regulator of these cellular and developmental processes according to specific threshold concentrations and cell- or tissue-specific responses. For years the concept of auxin concentration-dependent responses and the one of auxin sensitivity of a defined tissue were considered contradictory (Trewavas and Cleland 1983). To date, recent progress in our understanding of auxin biosynthesis, metabolism, and auxin transport established that the concentration gradient of auxin is a driving force for organogenesis and patterning, designating auxin as a plant morphogen. Differences in behavior of various plant cells to similar auxin environments or stimuli however indicate that they differ in their intrinsic capacity to respond, likely via modulation of their auxin signaling components and interaction with other plant hormone pathways but we are far from having an exhaustive understanding of these processes. The present review focuses on the molecular mechanisms of cell division and cell expansion and their regulation by auxin.

\section{AUXIN AND CELL DIVISION}

Mitotic cell division encompasses the sequence of events giving rise to the formation of two daughter cells. The cell cycle is divided into four phases: The replication of DNA characterizes the $S$ phase (synthesis) whereas segregation of the duplicated chromosomes and physical separation of the two daughter cells (cytokinesis) take place in mitosis or M phase. Two essential gap phases separate the $S$ and $M$ phases. The G1 phase, between mitosis and the entry into $S$ phase, and the G2 phase, between replication and mitosis, monitor whether the previous phase has been fully and accurately achieved before execution of the next one. Cell growth occurs mainly

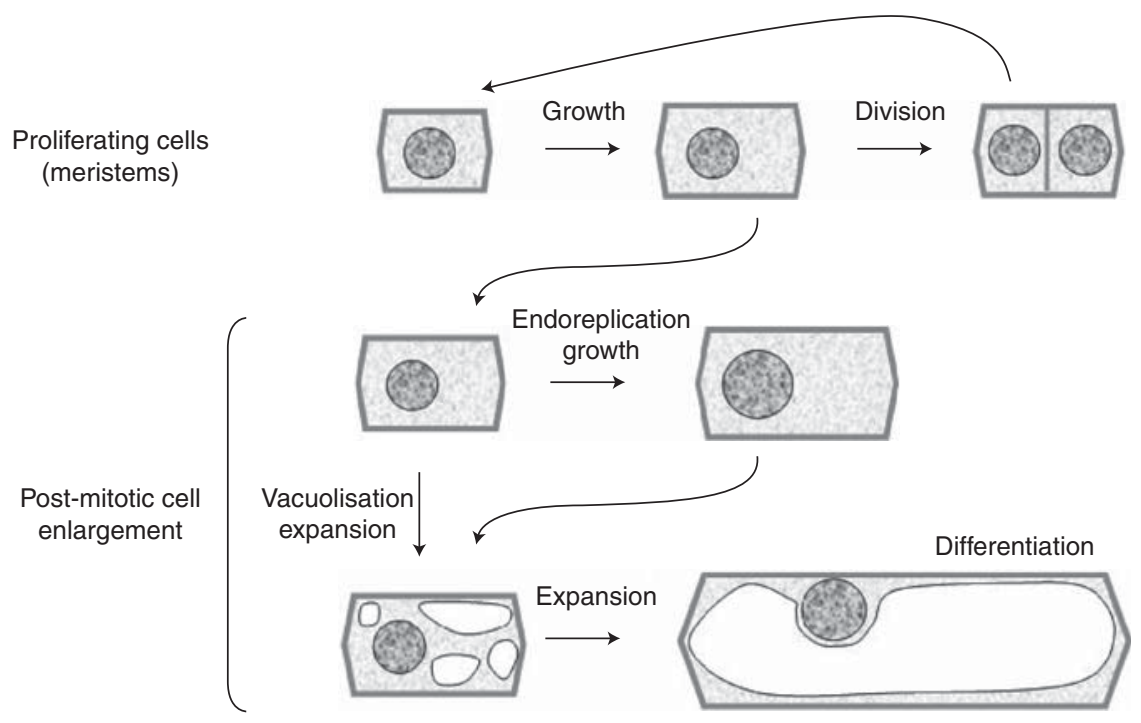

Figure 1. From cell proliferation to differentiation. Within plant meristems and cambial zones, new cells are formed by division. Between two successive rounds of division, the increase in size of these cells corresponds to cell growth. The main enlargement occurs after cells have left the meristem and often relies on a combination of two distinct processes: endoreplication and cell expansion. Cell expansion is an increase in cell size through vacuolization and enlargement of the vacuole leading to differentiation. 
within these two gap phases. The G1/S and G2/ $\mathrm{M}$ transitions are two critical regulatory steps of the cell cycle sometimes referred as cell-cycle restriction-or checkpoints. The plant cell cycle shares this highly ordered process with all eukaryotes and basic molecular mechanisms are mainly conserved (Fig. 2) (Inze and De Veylder 2006).

Because the first attempts to culture plant cells or tissues in vitro, the two phytohormones auxin and cytokinin were shown to play important roles in the induction of cell division and control of cell-cycle progression. Auxin starvation of suspension cells causes cell division arrest after a lag period ranging from a few hours to several days, depending on the synthetic auxin supplied in the initial culture medium (NAA or 2,4-D), the washing procedure of the cells before auxin deprivation (largely insufficient to remove pools of intracellular free auxin and with no or little effects on reversible conjugates that can be further converted into active auxin) or the experimental design (age of the subculture at deprivation,

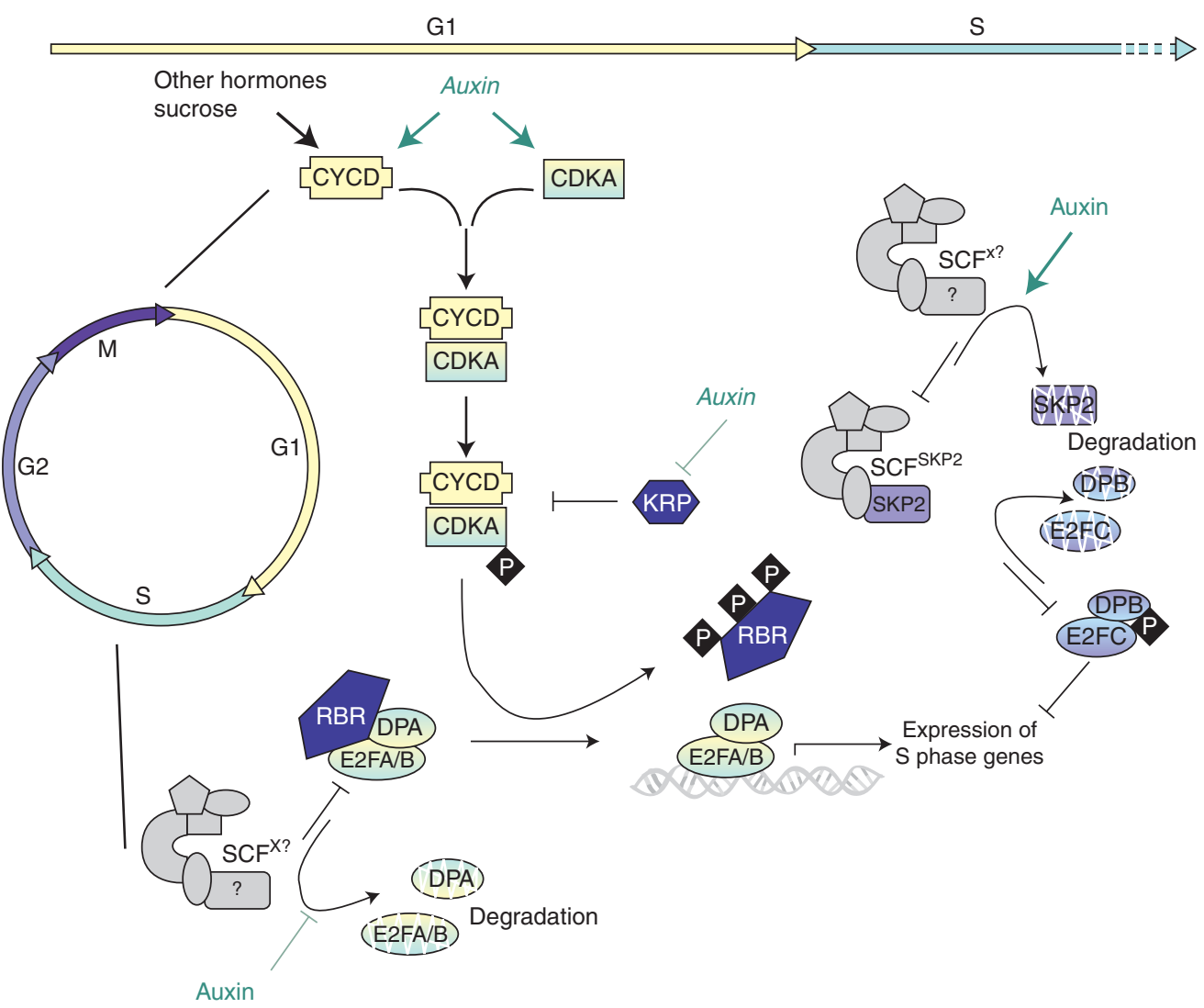

Figure 2. Auxin and the G1/S transition. The cell cycle is divided into four phases: DNA replication (S), mitosis (M), and two Gap phases (G1 and G2, between M/S, and S/M, respectively). The cycle starts in G1. During this phase, expression of D-type cyclins and cyclin-dependent kinase (CDKA) is induced by various signals including auxin. The CDKA/CYCD complex is activated by phosphorylation but can still be blocked by CDK inhibitors (KRP). Auxin was reported to reduce the expression of some KRPs. The active CDK/CYCD complex provokes phosphorylation of the transcriptional repressor retinoblastoma-related protein (RBR) thus promoting expression of genes essential for the beginning of the $S$ phase under the control of the E2FA/B and DPA complex. Auxin was shown to stabilize these transcriptional regulators. Later in S phase, E2Fc and DPB repress expression of $S$ phase genes. Degradation of these proteins is under the control of the E3 ubiquitine ligase SCF ${ }^{\mathrm{SKP} 2}$ and auxin was shown to increase the degradation of the F-box SKP2, thus indirectly stabilizing E2FC and DPB. 


\section{Perrot-Rechenmann}

measured parameters to evaluate division) (reviewed by (Doerner and Celenza 2000). Conversely, addition of auxin to arrested cells after deprivation of auxin leads to restoration of cell division. Auxin is necessary but not sufficient to stimulate cell division in cultured cells or plant tissues (Trehin et al. 1998; Stals and Inze 2001; Inze and De Veylder 2006) because the presence of cytokinin is also required. Cells cultured in the absence of exogenous cytokinin, such as BY2 tobacco cells (Nagata et al. 1992), produce it at least at critical phases of cell division while they are strictly dependent on exogenous auxin (Redig et al. 1996). All data emerging from cell culture studies suggest that auxin acts as a permissive signal for cell division providing the necessary competence to enter into the cell cycle (G1/S transition).

The role of auxin might, however, not end with the regulation of entry into the cell cycle. The specific roles of auxin at the various phases of the cell cycle in dividing cell suspension cultures has been hampered by the fact that auxin is required at the initial step of cell-cycle entry and thus its effects cannot easily be dissociated from this initial and critical step. The mechanisms by which auxin affects the cellcycle machinery are still far from being elucidated but recent data suggest that auxin acts on multiple targets and affects transcriptional regulation as well as protein turnover of core cell-cycle regulators.

\section{Basic Molecular Mechanisms of the Cell Cycle}

The completion of the Arabidopsis and rice genomes has permitted the identification of the majority of the core cell-cycle genes in plants. Recent advances have established that plant cell-cycle progression is controlled by an evolutionarily conserved molecular mechanism involving distinct combinations of cyclindependent kinase (CDK) and cyclin complexes which phosphorylate a number of substrates at the G1/S and/or G2/M transitions. Several key features are, however, unique to plant cells.

Within a CDK-cyclin complex, the cyclin plays a role in the selective interaction with substrate proteins whereas the CDK is the catalytic subunit responsible for the recognition of the serine or the threonine target motif in the substrate proteins (Dewitte and Murray 2003; Inze and De Veylder 2006) (Figure 2).

Plants contain up to 6 CDK types, among which CDKA, represented by a unique gene in Arabidopsis (CDKA;1) plays a pivotal role in both the G1/S and G2/M transitions. The plant specific CDKBs that accumulate in G2- and Mphases are essential for the $\mathrm{G} 2 / \mathrm{M}$ transition and cooperate with CDKA to regulate this transition (Magyar et al. 1997; Porceddu et al. 2001; Sorrell et al. 2001; Boudolf et al. 2004).

Plants contain more cyclins than described for others organisms (Vandepoele et al. 2002; Engler Jde et al. 2009). For instance, the Arabidopsis genome encodes at least 49 distinct cyclins belonging to seven classes. Cyclins show distinct regulation through the cell cycle and most of them contain a putative PEST sequence which may confer protein instability. D-type cyclins (CYCD) are often mentioned as sensors of external conditions, integrating hormonal or environmental signals and reporting to the cell on the favorable conditions for cell-cycle entry (Nieuwland et al. 2007). They associate with CDKA to regulate the G1/S transition. The resulting CDKA-CYCD is inactive until both proteins are phosphorylated by the CDK-activating kinase (CAK) pathway, which involves other types of CDKs (-D and $-F)$, an $\mathrm{H}$-type cyclin, and an unknown kinase phosphorylating the cyclin. Under developmental constraint or stress, the active CDKA-CYCD complex can still be inhibited by kip-related proteins (KRPs or CKIs for CDK inhibitors), which ensure a rapid exit from the cell cycle in response to antimitogenic stimuli. CYCDs contain a $\mathrm{LxCxE}$ amino-acid motif, which is responsible for their interaction with retinoblastoma-related protein (RBR), a negative regulator of cell proliferation (Nieuwland et al. 2007). Phosphorylation of RBR by the active CDKA-CYCD complex derepresses the transcriptional activity of E2FA/B (adenovirus E2 promoter binding Factor) and DP (Dimerization Protein) complexes, which control the expression of genes required for entry 
into S-phase and further progression into the cell cycle. The CDKA-CYCD complex may also phosphorylate the transcriptional repressor E2FC. E2FC and DPB form heterodimer and were shown to restrict cell division. Assembly of the complex is dependent on phosphorylation of E2FC and DPB proteins by CDK activity and both proteins are targeted for proteolysis by the $26 \mathrm{~S}$ proteasome after polyubiquitination by the SCF ${ }^{\text {SKP2A }}$ complex (del Pozo et al. 2006).

A-type cyclins are important from $S$ until $M$ phase, whereas B-type cyclins are critical for the control of the G2-to-M transition. After DNA replication, they associate with different CDKA or CDKB proteins. In contrast to animals, experimental data points also to an additional function of plant D-type cyclins at the G2-to-M transition (Schnittger et al. 2002; Kono et al. 2003; Koroleva et al. 2004). Activation of CDKA/B-CYC complexes is mediated by CAFs, which phosphorylate a critical CDK threonine residue whereas the activity of mitotic CDKs can be negatively regulated by WEE1, a kinase targeting other CDK phosphorylation residues (Thr14 and Tyr15). Active CDKA/B-CYC complexes trigger the G2/M transition by regulating the phosphorylation of downstream targets. Mitosis and exit from mitosis require the degradation of involved cyclins through ubiquitin-dependent proteolysis involving the anaphase-promoting complex (APC).

The specific and timely controlled degradation of cell-cycle regulatory proteins through the ubiquitin-dependent pathways is one of the critical mechanisms driving the unidirectional progression of the cell cycle. Both SCF and APC ubiquitin ligase E3 complexes are intimately involved in the regulation of the proteolysis of cell-cycle substrates. Phosphorylation of these regulatory proteins is frequently required before targeting to proteolysis (Genschik and Criqui 2007).

\section{Auxin Action on Cell Cycle}

Our understanding of auxin action on the cell cycle is still extremely fragmentary; primary evidence indicates that auxin acts on multiple targets, influencing directly or indirectly both transcriptional and posttranscriptional regulation.

Importantly, auxin was shown to induce the expression of CDKA;1, encoding the CDKA implicated throughout the cell cycle (Hemerly et al. 1993; Ferreira et al. 1994; Doerner and Celenza 2000). In tobacco cell suspension culture, auxin was reported to play an important role in the assembly of active CDKA-associated complexes (Harashima et al. 2007). Activation of the kinase activity may however require cytokinin for promoting the phosphorylation of the CDKA kinase as reported in Nicotiana plumbaginifolia cells (Zhang et al. 1996) (Fig. 2).

In Arabidopsis, CYCD3;1 was reported to be a rate-limiting factor for $\mathrm{G} 1 / \mathrm{S}$ transition (Menges et al. 2006). Expression of CYCD3;1 is regulated by the availability of nutrients but also by cytokinin, brassinosteroids, and auxin (Dewitte and Murray 2003). Based on global transcript profiling analysis in Arabidopsis, various cyclin genes are potentially regulated by auxin but it is not clear whether they are early responsive genes or if changes in their expression are indirect. Auxin responsive elements (AuxREs) can be found in promoter regions of various cyclins suggesting that they might be primary auxin responsive genes. In many cases, the functionality of these AuxREs has however not been shown.

Expression of KRP1 and KRP2, encoding two of the CDK inhibitors, was reported to be down-regulated after auxin treatment at least in specific root cells (Richard et al. 2001; Himanen et al. 2002).

Auxin also affects posttranscriptional regulation of cell-cycle components. Relative abundance of E2FB is increased in Arabidopsis cell suspension after auxin application and cotreatment with cycloheximide and auxin revealed that auxin increases E2FB protein stability (Magyar et al. 2005). By manipulating E2FB and DPA coexpression in tobacco BY2 cells, the same authors showed that elevated E2FB/ DPA support cell proliferation in the absence of auxin whereas control BY2 cells or cells overexpressing E2FA/DPA stop dividing and enlarge after starvation. The mechanisms by which E2FB proteolysis is controlled are still 


\section{Perrot-Rechenmann}

unknown; it is likely to be mediated by an SCF complex but the F-box has still to be identified. It will be interesting to determine whether the effect of auxin on E2FB stability is via a posttranslational modification of E2FB altering its recruitment by the SCF or if the primary affect of auxin is on the stability of another protein such as the putative F-box targeting E2FB degradation. Such a scenario has recently been reported for E2FC and DPB, two substrates of the $\mathrm{SCF}^{\text {SKP2A }}$ E3 ligase (Jurado et al. 2008). Auxin stimulates the degradation of the F-box SKP2A through a not-yet-identified ubiquitination/26S proteasome dependent pathway (APC as for SKP2 in mammals, $\mathrm{SCF}^{\mathrm{X}}$ or autoubiquitination) (Fig. 2). E2FC and DPB substrates were found to slightly accumulate in the hours following the exogenous application of auxin (Jurado et al. 2008) suggesting that the net balance between neosynthesis and degradation (potentially with the F-box) is positive. Interestingly, SKP2A is expressed from late $\mathrm{S}$-phase to $\mathrm{M}$ phase and is likely to mediate degradation of its substrates for cell-cycle progression during these phases. The precise timing of auxin-mediated degradation of SKP2A with respect to the phases of the cell cycle has not been determined yet.

In addition to effecting core cell-cycle regulators, auxin has been reported to regulate the expression of other genes or the turnover of proteins that are necessary for cell proliferation. For example, auxin was reported to stabilize a potato homolog of a human EBP1 (ErbB3 epidermal growth factor receptor binding protein) expressed transiently in Arabidopsis cells (Horvath et al. 2006). In mammals, EBP1 belongs to a family of DNA/RNA binding proteins implicated in cell proliferation, apoptosis, and differentiation; it inhibits transcription of E2F1 regulated genes and was proposed to be involved in protein translation (Monie et al. 2007). In plants, EBP1 seems to be required for expression of cell-cycle genes belonging to distinct phases such as CYCD3;1 (G1 and G1/ $\mathrm{S}$ ), ribonucleotide reductase 2 (RNR2, S-phase) or CDKB1;1 (G2 to $\mathrm{M}$ phase) in a doseand auxin-dependent manner. Modulation of EBP1 expression in Arabidopsis supports a role in cell proliferation of meristematic cells whereas it promotes expansion in nondividing cells (Horvath et al. 2006).

In synchronized BY2 cells, auxin was reported to induce the expression of telomerase at the S-phase, enhancing markedly the activity of telomerase during replication (Tamura et al. 1999). Telomerase is a specialized RNA-directed DNA polymerase that adds G-rich sequence elements onto the ends of linear eukaryotic chromosomes, and is essential for chromosome integrity and protection from exonucleolytic degradation. In mammals, telomerase activity is tightly associated with cell proliferation or immortalization. In plant cells, telomerase was proposed to have similar roles and to contribute to cell proliferation mechanisms. A zinc-finger protein related to the transcription factor family SUPERMAN, TAC1 (Telomerase Activator) and its potential target BT2, a BTB/POZ protein, were shown to link auxin signaling and telomerase expression (Ren et al. 2004; Ren et al. 2007).

The variety of targets of auxin action reported previously reflects the overall complexity of the mechanisms involved. In addition, cellcycle-modulated expression of auxin-responsive genes has been reported from large scale expression analysis in synchronized BY2 cells (Breyne et al. 2002) or Arabidopsis cells (Menges and Murray 2002; Menges et al. 2005). In tobacco, transcripts of $A R F 1$ and different members of the $A u x / I A A$ gene family were found to accumulate during early $M$ phase. Similarly IAA17 transcripts increased during the $\mathrm{M}$ phase in Arabidopsis cells, whereas IAA18 accumulated transiently in S-phase and no significant change was observed for $A R F$ genes in these cells. These data suggest that differential regulation of early auxin response genes might be necessary for cell-cycle progression but the cyclic nature of the process makes it difficult to determine what is the consequence of what.

\section{Auxin Signaling Pathways Controlling Cell Cycle}

Very little is known about the auxin signaling pathway(s) transducing the auxin signal to the 
cell-cycle machinery. Two auxin pathways with different levels of importance seem to be involved. One involves the auxin binding protein, $A B P 1$, and the other the already mentioned Aux/IAA/SCF ${ }^{\text {TIR1/AFB }}$ pathway. ABP1 was isolated through its capacity to bind auxin and, based on its involvement in the activation of ion fluxes at the plasma membrane in response to auxin, was characterized as an auxin receptor (Timpte 2001; Napier et al. 2002; Badescu and Napier 2006). Recent analysis of the effects of ABP1 functional inactivation in tobacco BY2 cells or in tobacco and Arabidopsis plants showed that ABP1 is critical for auxin regulation of the cell cycle. In BY2 cells the inactivation of ABP1 causes cell-cycle arrest. Cells accumulate in G1 and are unable to re-enter into the cell cycle even in the presence of auxin (David et al. 2007). Inactivation of the protein in synchronized cells revealed that the G2/M transition was also impaired. Local inactivation of ABP1 at the I1 position of the shoot apical meristem of tobacco plants results in rapid arrest of cell division with changes in the orientation of the cell division plate in cells which were progressing into the cell cycle at the time of inactivation. Similarly, aberrant cell divisions are observed in the suspensor and at the early stage of embryo development for the null abpl Arabidopsis mutant (Chen et al. 2001b). In Arabidopsis, inactivation of the protein at various stages of development showed that $\mathrm{ABP} 1$ is essential to maintain division in meristematic tissues and is critical for the maintenance of the root meristem (Braun et al. 2008; Tromas et al. 2009). ABP1 acts on the CYCD/ $\mathrm{RBR} / \mathrm{E} 2 \mathrm{~F}$ pathway regulating the G1/S transition (Tromas et al. 2009). The cell-cycle target of ABP1 action is however not precisely identified and the signaling pathway downstream of ABP1 has still to be resolved.

Characterization of Arabidopsis mutants affected in auxin responses confirms that regulation of gene expression in response to auxin via the AUX/IAA/SCF ${ }^{\text {TIR1AFB }}$ pathway is involved in the auxin control of the cell cycle as some of these mutants show moderate but significant defects in cell division. The relation between this pathway and regulation of core cell-cycle regulators is poorly documented with the notable exception of the initiation of lateral root formation (reviewed by De Smet et al. 2006; Peret et al. 2009). As mentioned previously the regulatory untranslated 5' sequence of various core cell cycle genes contains putative AuxREs and might be directly induced in response to auxin. Gene expression usually results from combinatorial regulation and the relative importance of an AuxRE within a given promoter has still to be determined gene by gene. To date, there is no evidence indicating that cell cycle proteins are substrates of the $\mathrm{SCF}^{\mathrm{TIR} 1 / \mathrm{AFB}}$ complex. Conversely for those F-box proteins responsible for degradation of cell cycle regulators, there is no evidence for a direct role of auxin in promoting interaction between the F-box and the substrate as for TIR1/AFB and Aux/IAA substrates. The effect of auxin on the degradation of cell-cycle proteins is thus far from being understood.

\section{AUXIN AND CELL EXPANSION/ ELONGATION}

Cell expansion is an increase in cell size accompanying the process of plant growth. Cells leaving meristematic zones often enlarge to involved or thousands of times their original size. This increase in size usually results from the combination of two processes: The increase in cell ploidy level by endoreplication (successive rounds of DNA replication with no mitosis), and the complex process of cell expansion, which is driven by internal turgor pressure and restricted by the ability of cell walls to extend (Fig. 1).

Endoreplication occurs when the cell cycle is truncated such that either mitosis or cytokinesis is skipped between rounds of DNA replication. The result is the formation of cells with increasing ploidy. In most Arabidopsis shoot tissues, a positive correlation was reported between the degree of ploidy and cell size. Conversely in roots, such correlation has not been observed however the switch from mitotic cycles to endocycles is coupled with the transition between the root meristem and cell differentiation (Beemster et al. 2002; Ishida et al. 


\section{Perrot-Rechenmann}

2009). By modulating the levels of cell-cycle regulators that are involved in both the mitotic cycle and the endocycle, auxin is likely to play a major role in the regulation of endoreplication (see previous discussion). For example E2FC, which acts as a negative regulator of cell division, was shown to be necessary for endoreplication. By modulating the stability of E2FC, auxin is likely involved to maintain a balance between proliferation and endoreplication (del Pozo et al. 2006). In roots, the mitotic to endocycle transition was recently proposed to be regulated by auxin and cytokinin, the combination of low auxin and increased cytokinin facilitating the switch from mitotic cells to endocycle and differentiation (Ishida T. and Sugimoto K., personal communication; Dello Ioio et al. 2008). The use of specific inhibitor of AUX/IAA/SCF TIR1AFB pathway suggests that this auxin signaling pathway is involved in the transition from mitotic cycle to the endocycle (Ishida T. and Sugimoto K., personal communication).

Plant cell expansion requires uptake of water, which is then stored in vacuoles, and irreversible extension of the cell wall, which includes wall loosening (short time frame) and deposition of new wall material (long time frame). Auxin is one of the major stimuli affecting these mechanisms but it is essential to keep in mind that cell expansion is also under the control of many other stimuli, such as blue light and most of the other phytohormones. Auxin-dependent cell expansion follows a dose-response curve in which high concentrations are inhibitory (Barbier-Brygoo et al. 1991; Evans et al. 1994). The apparent response-maxima varies according to both the plant and the organ with shoots and roots showing differences in sensitivity of several orders of magnitude. Exogenous application of micromolar auxin stimulates cell expansion in stems and in almost all shoot tissues, whereas application of over $10^{-9}$ or $10^{-8} \mathrm{M}$ auxin inhibits cell elongation in roots (cf inhibition of root growth assay). The molecular mechanisms underlying these differences in auxin sensitivity remain elusive. Cross-talk with other signals is often evoked as well as a differential or tissue specific expression of
AUX/IAA repressors or ARFs but experiments to investigate these or other mechanisms responsible for cell sensitivity are needed.

\section{From Cell Wall Loosening to Expansion}

Focus is given here to the mechanisms that sustain auxin-induced cell expansion. Plant cells are surrounded by a complex and dynamic wall, which plays a critical role during development in establishing cell size and cell shape. The structure of the primary cell wall is formed by a network of crystalline cellulose microfibrils interlinked with hemicelluloses (mainly xyloglucan or arabinoxylan in seed plants). This network is embedded in a matrix of pectins and also contains a small amount of cell-wall proteins (reviewed by Darley et al. 2001; Cosgrove 2005; Humphrey et al. 2007).

Rapid enlargement requires wall loosening, that involves modification of the molecular interactions within the cell-wall network (but not of its composition), resulting in relaxation of wall tension. Current models propose that wall loosening results from breakage of crosslinks, cleavage of hemicellulose polymers, or weakening of the noncovalent bonds facilitating hemicellulose sliding along the cellulose scaffold. Expansins have been identified as major wall-loosening agents (Cosgrove 2000; Kende et al. 2004; Sampedro and Cosgrove 2005). These cell wall proteins are activated by acidification and, in a range of $\mathrm{pH}$ between 4.5 and 6 , are thought to disrupt noncovalent binding between cellulose and hemicelluloses. In addition to expansins, xyloglucan endotransglycosylase/hydrolases (XTHs), which cut and paste xyloglucans (Rose et al. 2002), or endoglucanases, which hydrolyse glucosidic bonds, may also contribute to wall loosening by modifying wall properties or to cell expansion by facilitating integration of new wall materials (Fig. 3).

Auxin was shown to induce rapid cell elongation in stem, coleoptile, or hypocotyl segments within minutes after auxin treatment (Rayle and Cleland 1992; Cleland 1995). This rapid effect is believed to result from the activation of a proton pump ATPase at the plasma membrane, inducing extrusion of $\mathrm{H}^{+}$, 


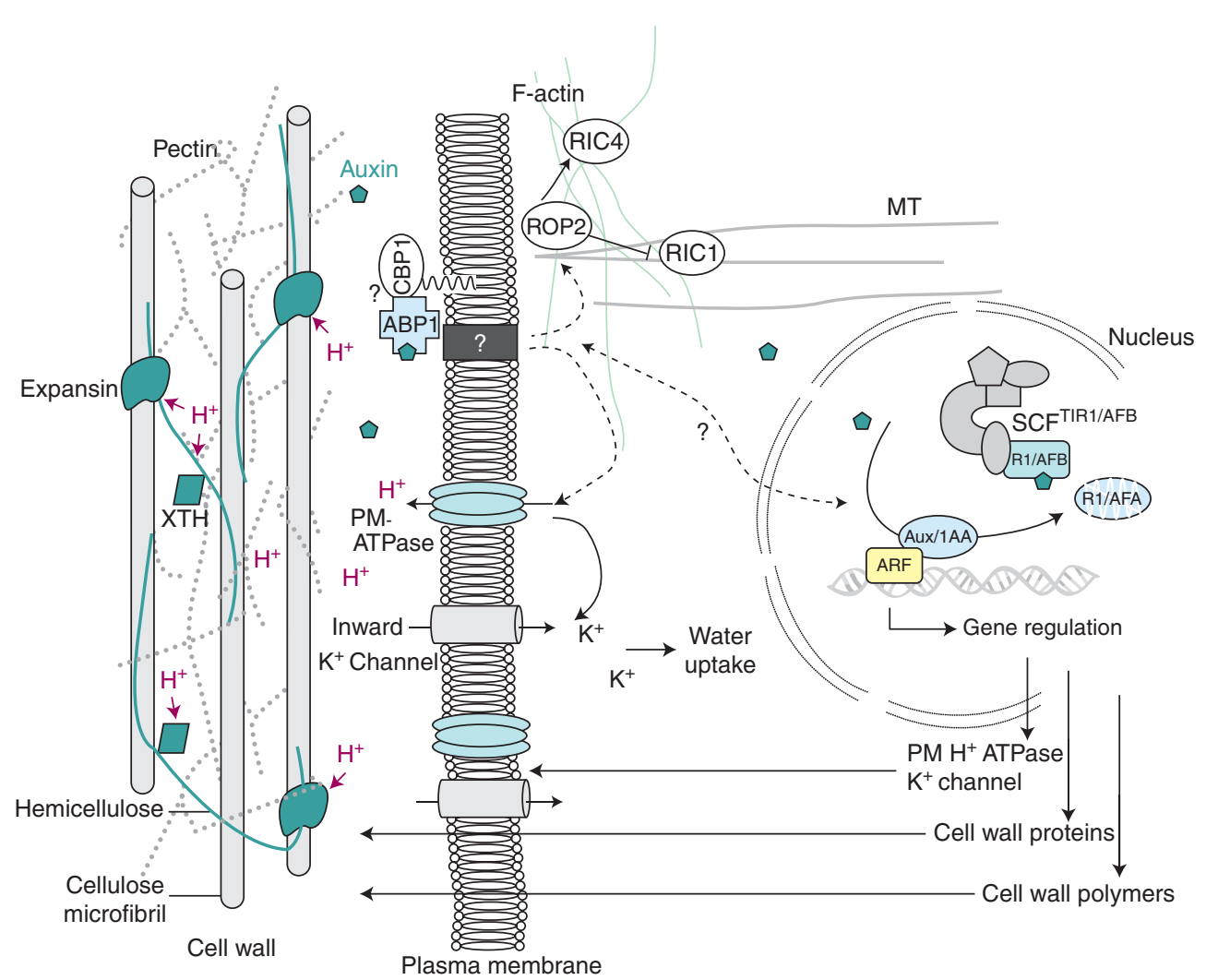

Figure 3. Auxin-induced cell wall loosening and expansion. The scheme represents the cell wall/plasma membrane/cytoskeleton continuum and the consequences of auxin action. Auxin is perceived by the auxin receptor $\mathrm{ABP} 1$, which interacts with unknown membrane-associated proteins at the plasma membrane (such as the putative candidate GPI-anchored protein CBP1) (Shimomura 2006). This activates the proton pump ATPase, provoking the acidification $\left(\mathrm{H}^{+}\right)$of the extracellular space, the activation of cell wall proteins such as expansins and xyloglucan endotransglycosylase/hydrolases (XTH), which mediate cell wall loosening by acting on the cell wall polysaccharide network. Polysaccharides forming the cell wall are cellulose microfibrils, cross-linked hemicelluloses, and pectins. Activation of the $\mathrm{H}+$ ATPase also induces hyperpolarization of the plasma membrane and activation of $\mathrm{K}+$ inward rectifying channels, essential for the uptake of water sustaining cell expansion. Auxin also enhances these effects by inducing the expression of genes encoding plasma membrane ATPase, $\mathrm{K}+$ channels, expansins, and cell wall remodelling enzymes and promotes exportation of new cell wall material. Auxin is likely to act on actin microfilaments and microtubules via the modulation of ROP GTPases.

extracellular acidification, activation of expansins, and subsequent wall loosening. Activation of the plasma membrane $\mathrm{H}^{+}$ATPase causes hyperpolarization of the membrane potential and activation of voltage-dependent $\mathrm{K}^{+}$inward channels (Rück et al. 1993; Philippar et al. 1999; Thiel and Weise 1999; Philippar et al. 2004). Uptake of $\mathrm{K}^{+}$is likely to contribute to the water uptake necessary to sustain expansion. In addition to the stimulation of their activity, auxin also induces expression of both $\mathrm{H}+$ ATPase and $\mathrm{K}+$ channels, for example ZmMK1 in maize coleoptiles (Frias et al. 1996; Philippar et al. 1999) (Fig. 3).

On a long term scale, new material is integrated within the cell wall, thus preventing the wall from becoming thinner and maintaining integrity of the wall architecture on extension. Nascent xyloglucan chains are exported to the cell wall matrix and are incorporated into existing xyloglucans. XTHs were proposed to mediate this process. Interestingly, some members of the XTH gene family, as well as several expansins or $\beta$-glucanases were shown to be up-regulated 


\section{Perrot-Rechenmann}

by auxin (Kotake et al. 2000; Yokoyama and Nishitani 2001; Swarup et al. 2008). It is however not always clear whether these genes are early responsive genes, are secondary responsive genes downstream of Aux/IAA-ARF targets, or if their activation results from a change in biosynthesis of another hormone (Cho and Cosgrove 2000; Cho and Cosgrove 2002). Interestingly, two expansin genes, EXPA1 and EXPA8, were shown to be rapidly and locally up-regulated in hypocotyls subjected to gravitropic or phototropic stimuli, and only in the section of the hypocotyl destined to elongate (Esmon et al. 2006). Increase in EXPA1 and EXPA8 mRNAs was reported before the macroscopic curvature was observed; suggesting that cell expansion should be enhanced by increased expansin delivery at the cell wall in response to auxin.

Many early auxin responsive genes have been initially isolated from auxin-induced expanding tissues, suggesting they are important for this process. Various gain of function mutants of the AUX/IAA repressor family (e.g., axr5/iaa1, shy2/iaa3, axr2/iaa7, or axr3/iaa17) show short hypocotyls, tropic alteration, or curled leaves, all of which evoke defects in cell expansion (Liscum and Reed 2002; Mockaitis and Estelle 2008), suggesting that auxin mediated degradation of these repressors is required for cell expansion. Thus, by controlling the half-life of the AUX/IAA repressors, the SCF ${ }^{\mathrm{TIR} 1}$ pathway is undoubtedly important for the activation of gene expression involved in the control of auxin-induced cell expansion (Mockaitis and Estelle 2008).

\section{ABP1 and Cell Expansion}

Various lines of evidence, mainly relying on electrophysiological experiments and use of a whole series of ABP1 molecular tools (specific monoclonal and polyclonal antibodies, carboxy-terminal synthetic peptides, recombinant wild-type and mutated proteins) support the hypothesis that ABP1 is involved in the initial perception of auxin at the outer face of the plasma membrane and induces the activation of $\mathrm{H}^{+}$ATPase and $\mathrm{K}^{+}$inward channels (Rück et al. 1993; Thiel et al. 1993; Barbier-Brygoo et al. 1996; Fellner et al. 1996; Leblanc et al. 1999a; Leblanc et al. 1999b; David et al. 2001) (Fig. 3). In addition ABP1 was shown to mediate the auxin-induced enlargement (or swelling) of protoplasts of maize coleoptiles and Arabidopsis hypocotyls (Steffens et al. 2001). Analysis of the swelling response of protoplasts of pea stem epidermal cells revealed a biphasic dose response curve to IAA, one phase being dependent on ABP1 but not the other, suggesting that at least in these epidermal cells another pathway is involved (Yamagami et al. 2004). A possible candidate for the second phase was a soluble auxin binding protein, ABP57, initially isolated from rice with anti-BSA antibodies and reported to activate $\mathrm{H}^{+}$ATPase in the presence of auxin (Kim et al. 2001). The corresponding gene was however cloned recently in rice and found in the maize genome but intriguingly not in the Arabidopsis genome thus questioning its relative importance in basic auxin mediated responses (Lee et al. 2009).

Additional lines of evidence coming from in vivo modulation of $\mathrm{ABP} 1$ expression or activity have shown the importance of ABP1 in auxinmediated cell expansion, at least in shoot tissues. Overexpression of ABP1 in tobacco leaves enhances the sensitivity of guard cell $\mathrm{K}+$ channels to auxin (Bauly et al. 2000) and shifts the plasma membrane hyperpolarization of protoplasts to lower auxin concentrations (BarbierBrygoo H., personal communication). Inducible overexpression of ABP1 leads to an increased expansion of some leaf tissues in response to auxin (Jones et al. 1998; Chen et al. 2001a). The null abpl mutant in Arabidopsis, in addition to cell division defects, shows altered cell expansion (Chen et al. 2001b). Finally, functional inactivation of ABP1, by use of conditional antisense or conditional immunorepression strategies, confirmed the critical role of the protein in the control of cell expansion in leaf tissues even in cells with increased ploidy (Braun et al. 2008). Altogether, these data show that ABP1 is essential for auxin-dependent cell expansion during leaf growth. The involvement of $A B P 1$ begins with the activation of the transduction chain at the plasma membrane thus 
resulting in wall loosening and cell enlargement. ABP1 was also reported to modulate the expression of $A U X / I A A$ genes suggesting that its role is not restricted to the regulation of ion fluxes at the plasma membrane and that it influences the SCF ${ }^{\text {TIR1 }}$ pathway (Braun et al. 2008).

As mentioned earlier, expanding root and leaf cells differ considerably in their responsiveness to auxin. Interestingly, the inactivation of $\mathrm{ABP} 1$ in roots prompts basal meristematic cells to elongate and confers resistance to IAA (Tromas et al. 2009), implicating ABP1 in the modulation of sensitivity to auxin and as a negative regulator of cell expansion in roots. It is likely that the peculiarity of cell expansion in roots largely relies on the cross talk between auxin and cytokinin (Moubayidin et al. 2009). Divergence between shoot and root tissues illustrates the importance of the developmental context when investigating the mechanisms of hormone regulation in relation with a defined cellular response.

\section{Auxin and the Cytoskeleton}

An interesting concept has emerged from various authors who proposed that there is a continuum between the cell wall, the plasma membrane, and the cytoskeleton, linking external and internal compartments (Wyatt and Carpita 1993; Baluska et al. 2003; Paradez et al. 2006). Whereas plant turgor is supposed to be isotropic, cell expansion is often directional. Within a tissue, initial patterning and neighboring cells contribute to determine the orientation of cell expansion. The orientation of microtubules (MT) and organization of actin microfilaments are important for directional cell expansion (Wasteneys and Galway 2003). Auxin has been shown to affect patterning and organization of the cytoskeleton. Depending on the experimental conditions, the plant material and plant cell type, auxin was reported to induce cortical MT reorientation (Blancaflor and Hasenstein 1993; Blancaflor and Hasenstein 1995; Takesue and Shibaoka 1998; Takesue and Shibaoka 1999) or disintegration of the MT cytoskeleton (Baluska et al. 1996). In addition auxin-induced cell expansion was also shown to correlate with an auxin-dependent reorganization of actin filaments into fine cortical strands (Waller et al. 2002; Holweg et al. 2004). More recently, a complex regulatory loop between actin and auxin, more specifically auxin transport, was reported (Dhonukshe et al. 2008; Nick et al. 2009). Accumulating evidence supports that the effects of auxin on cytoskeleton involve ROP GTPases and their effectors RICs proteins (Fu et al. 2002; Gu et al. 2004; Yang and Fu 2007) (Fig. 3). Because of space limitations, the importance of ROPs in auxindependent vesicle trafficking, auxin transport, and auxin-induced cell expansion cannot be discussed here but merits special mention (Xu and Scheres 2005; Yang and Fu 2007).

\section{CONCLUDING REMARKS}

Much progress has been made in the identification of components taking part in the control of cell division and cell expansion. The final number, size, and shape of plant organs largely rely on the coordination of these cellular responses and auxin plays a central role in these processes. Much has yet to be learned about the complex network of regulation activated by auxin and how the auxin signal is differentially transduced in a variety of downstream responses depending on the cell, the organ, or the environment. Elucidating the auxin signaling pathways involved and how the two types of auxin receptors, TIR1/AFB and ABP1, cooperate to control cellular responses to auxin are critical challenges for the coming years.

\section{ACKNOWLEDGMENTS}

I warmly thank Barbara Kunkel, Cécile Raynaud, and Alexandre Tromas for critical reading and useful comments. The author is supported by the CNRS.

\section{REFERENCES}

Badescu GO, Napier RM. 2006. Receptors for auxin: Will it all end in TIRs? Trends Plant Sci 11: 217-223.

Baluska F, Barlow PW, Volkmann D. 1996. Complete disintegration of the microtubular cytoskeleton precedes its 


\section{Perrot-Rechenmann}

auxin-mediated reconstruction in postmitotic maize root cells. Plant Cell Physiol 37: 1013-1021.

Baluska F, Samaj J, Wojtaszek P, Volkmann D, Menzel D. 2003. Cytoskeleton-plasma membrane-cell wall continuum in plants. Emerging links revisited. Plant Physiol 133: $482-491$.

Barbier-Brygoo H, Ephritikhine G, Klämbt D, Maurel C, Pälme K, Schell J, Guern J. 1991. Perception of the auxin signal at the plasma membrane of tobacco mesophyll protoplasts. Plant J 1: 83-93.

Barbier-Brygoo H, Zimmermann S, Thomine S, White IR, Millner P, Guern J. 1996. Elementary auxin response chains at the plasma membrane involve external abp1 and multiple electrogenic ion transport proteins. Plant Growth Regulation 18: 23-28.

Bauly JM, Sealy IM, Macdonald H, Brearley J, Droge S, Hillmer S, Robinson DG, Venis MA, Blatt MR, Lazarus $\mathrm{CM}$, et al. 2000. Overexpression of auxin-binding protein enhances the sensitivity of guard cells to auxin. Plant Physiol 124: 1229-1238.

Beemster GT, De Vusser K, De Tavernier E, De Bock K, Inze D. 2002. Variation in growth rate between Arabidopsis ecotypes is correlated with cell division and A-type cyclin-dependent kinase activity. Plant Physiol 129: 854-864.

Blancaflor EB, Hasenstein KH. 1993. Organization of cortical microtubules in graviresponding maize roots. Planta 191: 231-237.

Blancaflor EB, Hasenstein KH. 1995. Time course and auxin sensitivity of cortical microtubule reorientation in maize roots. Protoplasma 185: 72-82.

Boudolf V, Barroco R, Engler Jde A, Verkest A, Beeckman T, Naudts M, Inze D, De Veylder L. 2004. B1-type cyclindependent kinases are essential for the formation of stomatal complexes in Arabidopsis thaliana. Plant Cell 16: 945-955.

Braun N, Wyrzykowska J, Muller P, David K, Couch D, Perrot-Rechenmann C, Fleming AJ. 2008. Conditional repression of AUXIN BINDING PROTEIN1 reveals that it coordinates cell division and cell expansion during postembryonic shoot development in Arabidopsis and tobacco. Plant Cell 10: 2746-2762.

Breyne P, Dreesen R, Vandepoele K, De Veylder L, Van Breusegem F, Callewaert L, Rombauts S, Raes J, Cannoot B, Engler G, et al. 2002. Transcriptome analysis during cell division in plants. Proc Natl Acad Sci 99: 14825-14830.

Chen JG, Shimomura S, Sitbon F, Sandberg G, Jones AM. 2001a. The role of auxin-binding protein 1 in the expansion of tobacco leaf cells. Plant J 28: 607-617.

Chen JG, Ullah H, Young JC, Sussman MR, Jones AM. 2001b. ABP1 is required for organized cell elongation and division in Arabidopsis embryogenesis. Genes Dev 15: $902-911$.

Cho HT, Cosgrove DJ. 2000. Altered expression of expansin modulates leaf growth and pedicel abscission in Arabidopsis thaliana. Proc Natl Acad Sci 97: 9783-9788.

Cho HT, Cosgrove DJ. 2002. Regulation of root hair initiation and expansin gene expression in Arabidopsis. Plant Cell 14: 3237-3253.

Cleland RE. 1995. Auxin and cell elongation. In Plant hormones: Physiology, biochemistry and molecular biology (ed. P.J. Davies), pp. 214-227. Kluwer Academic Publishers.

Cosgrove DJ. 2000. Loosening of plant cell walls by expansins. Nature 407: 321-326.

Cosgrove DJ. 2005. Growth of the plant cell wall. Nat Rev Mol Cell Biol 6: 850-861.

Darley CP, Forrester AM, McQueen-Mason SJ. 2001. The molecular basis of plant cell wall extension. Plant Mol Biol 47: 179-195.

David K, Carnero-Diaz E, Leblanc N, Monestiez M, Grosclaude J, Perrot-Rechenmann C. 2001. Conformational dynamics underlie the activity of the auxin-binding protein, Nt-abp1. J Biol Chem 276: 34517-34523.

David KM, Couch D, Braun N, Brown S, Grosclaude J, Perrot-Rechenmann C. 2007. The auxin-binding protein 1 is essential for the control of cell cycle. Plant J 50: 197-206.

De Smet I, Vanneste S, Inze D, Beeckman T. 2006. Lateral root initiation or the birth of a new meristem. Plant Mol Biol 60: 871-887.

del Pozo JC, Diaz-Trivino S, Cisneros N, Gutierrez C. 2006. The balance between cell division and endoreplication depends on E2FC-DPB, transcription factors regulated by the ubiquitin-SCFSKP2A pathway in Arabidopsis. Plant Cell 18: 2224-2235.

Dello Ioio R, Nakamura K, Moubayidin L, Perilli S, Taniguchi M, Morita MT, Aoyama T, Costantino P, Sabatini S. 2008. A genetic framework for the control of cell division and differentiation in the root meristem. Science 322: $1380-1384$.

Dewitte W, Murray JA. 2003. The plant cell cycle. Annu Rev Plant Biol 54: 235-264.

Dhonukshe P, Grigoriev I, Fischer R, Tominaga M, Robinson DG, Hasek J, Paciorek T, Petrasek J, Seifertova D Tejos R, et al. 2008. Auxin transport inhibitors impair vesicle motility and actin cytoskeleton dynamics in diverse eukaryotes. Proc Natl Acad Sci 105: 4489-4494.

Doerner P, Celenza J. 2000. How are plant growth regulators involved in cell cycle control? In Plant hormone research (ed. K. Palme, J. Schell), pp. 1-27. Springer.

Engler Jde A, De Veylder L, De Groodt R, Rombauts S, Boudolf V, De Meyer B, Hemerly A, Ferreira P, Beeckman T, Karimi M, et al. 2009. Systematic analysis of cell-cycle gene expression during Arabidopsis development. Plant J 59: 645-660.

Esmon CA, Tinsley AG, Ljung K, Sandberg G, Hearne LB, Liscum E. 2006. A gradient of auxin and auxin-dependent transcription precedes tropic growth responses. Proc Natl Acad Sci 103: 236-241.

Evans ML, Ishikawa H, Estelle MA. 1994. Responses of Arabidopsis roots to auxin studied with high temporal resolution: Comparison of wild type and auxin-response mutants. Planta 194: 215-222.

Fellner M, Ephritikhine G, Barbier-Brygoo H, Guern J. 1996. An antibody raised to a maize auxin-binding protein has inhibitory effects on cell division of tobacco mesophyll protoplasts. Plant Physiol Biochem 34: 133-138.

Ferreira PC, Hemerly AS, Engler JD, van Montagu M, Engler G, Inze D. 1994. Developmental expression of the Arabidopsis cyclin gene cyc1At. Plant Cell 6: 1763-1774. 
Frias I, Caldeira MT, Perez-Castineira JR, Navarro-Avino JP, Culianez-Macia FA, Kuppinger O, Stransky H, Pages M, Hager A, Serrano R. 1996. A major isoform of the maize plasma membrane $\mathrm{H}(+)$-ATPase: Characterization and induction by auxin in coleoptiles. Plant Cell 8: $1533-1544$.

Fu Y, Li H, Yang Z. 2002. The ROP2 GTPase controls the formation of cortical fine F-actin and the early phase of directional cell expansion during Arabidopsis organogenesis. Plant Cell 14: 777-794.

Genschik P, Criqui MC. 2007. The UPS: An engine that drives the cell cycle. in Cell cycle control and plant development (ed. Inze D.), pp. 87-113. Blackwell Publishing.

Gu Y, Wang Z, Yang Z. 2004. ROP/RAC GTPase: An old new master regulator for plant signaling. Curr Opin Plant Biol 7: 527-536.

Harashima H, Kato K, Shinmyo A, Sekine M. 2007. Auxin is required for the assembly of A-type cyclin-dependent kinase complexes in tobacco cell suspension culture. J Plant Physiol 164: 1103-1112.

Hemerly AS, Ferreira P, de Almeida Engler J, Van Montagu M, Engler G, Inze D. 1993. cdc2a expression in Arabidopsis is linked with competence for cell division. Plant Cell 5: $1711-1723$

Himanen K, Boucheron E, Vanneste S, de Almeida Engler J, Inze D, Beeckman T. 2002. Auxin-mediated cell cycle activation during early lateral root initiation. Plant Cell 14: 2339-2351.

Holweg C, Susslin C, Nick P. 2004. Capturing in vivo dynamics of the actin cytoskeleton stimulated by auxin or light. Plant Cell Physiol 45: 855-863.

Horvath BM, Magyar Z, Zhang Y, Hamburger AW, Bako L, Visser RG, Bachem CW, Bogre L. 2006. EBP1 regulates organ size through cell growth and proliferation in plants. Embo J 25: 4909-4920.

Humphrey TV, Bonetta DT, Goring DR. 2007. Sentinels at the wall: Cell wall receptors and sensors. New Phytol 176: 7-21.

Inze D, De Veylder L. 2006. Cell cycle regulation in plant development. Annu Rev Genet 40: 77-105.

Ishida T, Fujiwara S, Miura K, Stacey N, Yoshimura M, Schneider K, Adachi S, Minamisawa K, Umeda M, Sugimoto K. 2009. SUMO E3 ligase HIGH PLOIDY2 regulates endocycle onset and meristem maintenance in Arabidopsis. Plant Cell 21: 2284-2297.

Jones AM, Im KH, Savka MA, Wu MJ, Dewitt NG, Shillito R, Binns AN. 1998. Auxin-dependent cell expansion mediated by overexpressed auxin-binding protein 1 . Science 282: $1114-1117$.

Jurado S, Trivino SD, Abraham Z, Manzano C, Gutierrez C, Del Pozo C. 2008. SKP2A protein, an F-box that regulates cell division, is degraded via the ubiquitin pathway. Plant Signal Behav 3: 810-812.

Kende H, Bradford K, Brummell D, Cho HT, Cosgrove D, Fleming A, Gehring C, Lee Y, McQueen-Mason S, Rose $\mathrm{J}$, et al. 2004. Nomenclature for members of the expansin superfamily of genes and proteins. Plant Mol Biol 55: 311-314.

Kim YS, Min JK, Kim D, Jung J. 2001. A soluble auxinbinding protein, ABP57. Purification with anti-bovine serum albumin antibody and characterization of its mechanistic role in the auxin effect on plant plasma membrane H+-ATPase. J Biol Chem 276: 10730-10736.

Kono A, Umeda-Hara C, Lee J, Ito M, Uchimiya H, Umeda M. 2003. Arabidopsis D-type cyclin CYCD4;1 is a novel cyclin partner of B2-type cyclin-dependent kinase. Plant Physiol 132: 1315-1321.

Koroleva OA, Tomlinson M, Parinyapong P, Sakvarelidze L, Leader D, Shaw P, Doonan JH. 2004. CycD1, a putative G1 cyclin from Antirrhinum majus, accelerates the cell cycle in cultured tobacco BY-2 cells by enhancing both G1/S entry and progression through S and G2 phases. Plant Cell 16: 2364-2379.

Kotake T, Nakagawa N, Takeda K, Sakurai N. 2000. Auxin-induced elongation growth and expressions of cell wall-bound exo- and endo- $\beta$-glucanases in barley coleoptiles. Plant Cell Physiol 41: 1272-1278.

Leblanc N, Perrot-Rechenmann C, Barbier-Brygoo H. 1999b. The auxin-binding protein Nt-ERabp1 alone activates an auxin-like transduction pathway. FEBS Letters 449: $57-60$

Leblanc N, David K, Grosclaude J, Pradier JM, BarbierBrygoo H, Labiau S, Perrot-Rechenmann C. 1999a. A novel immunological approach establishes that the auxin-binding protein, $\mathrm{Nt}$-abp1, is an element involved in auxin signaling at the plasma membrane. J Biol Chem 274: 28314-28320.

Lee K, Kim M, Kwon YJ, Kim M, Kim YS, Kim D. 2009. Cloning and characterization of a gene encoding ABP57, a soluble auxin-binding protein. Plant Biotechnology Reports 10.1007/s11816-009-0101-z.

Liscum E, Reed JW. 2002. Genetics of Aux/IAA and ARF action in plant growth and development. Plant Mol Biol 49: $387-400$.

Magyar Z, De Veylder L, Atanassova A, Bako L, Inze D, Bogre L. 2005. The role of the Arabidopsis E2FB transcription factor in regulating auxin-dependent cell division. Plant Cell 17: 2527-2541.

Magyar Z, Meszaros T, Miskolczi P, Deak M, Feher A, Brown S, Kondorosi E, Athanasiadis A, Pongor S, Bilgin M, et al. 1997. Cell cycle phase specificity of putative cyclindependent kinase variants in synchronized alfalfa cells. Plant Cell 9: 223-235.

Menges M, Murray JA. 2002. Synchronous Arabidopsis suspension cultures for analysis of cell-cycle gene activity. Plant J 30: 203-212.

Menges M, de Jager SM, Gruissem W, Murray JA. 2005. Global analysis of the core cell cycle regulators of Arabidopsis identifies novel genes, reveals multiple and highly specific profiles of expression and provides a coherent model for plant cell cycle control. Plant J 41: 546-566.

Menges M, Samland AK, Planchais S, Murray JA. 2006. The D-type cyclin CYCD3; 1 is limiting for the G1-to-S-phase transition in Arabidopsis. Plant Cell 18: 893-906.

Mockaitis K, Estelle M. 2008. Auxin receptors and plant development: A new signaling paradigm. Annu Rev Cell Dev Biol 24: 55-80.

Monie TP, Perrin AJ, Birtley JR, Sweeney TR, Karakasiliotis I, Chaudhry Y, Roberts LO, Matthews S, Goodfellow IG, Curry S. 2007. Structural insights into the transcriptional and translational roles of Ebpl. Embo J 26: 3936-3944. 


\section{Perrot-Rechenmann}

Moubayidin L, Di Mambro R, Sabatini S. 2009. Cytokininauxin crosstalk. Trends Plant Sci.

Nagata T, Nemoto Y, Hasezawa S. 1992. Tobacco BY-2 cell line as the "HeLa" cell in the cell biology of higher plant. Int Rev Cytol 132: 1-30.

Napier RM, David KM, Perrot-Rechenmann C. 2002. A short history of auxin-binding proteins. Plant Mol Biol 49: 339-348.

Nick P, Han MJ, An G. 2009. Auxin stimulates its own transport by shaping actin filaments. Plant Physiol 151: 155- 167 .

Nieuwland J, Menges M, Murray JAH. 2007. The plant cyclins. In Cell cycle control and plant development (ed. D. Inze), pp. 31-61. Blackwell Publishing.

Paradez A, Wright A, Ehrhardt DW. 2006. Microtubule cortical array organization and plant cell morphogenesis. Curr Opin Plant Biol 9: 571-578.

Peret B, De Rybel B, Casimiro I, Benkova E, Swarup R, Laplaze L, Beeckman T, Bennett MJ. 2009. Arabidopsis latera root development: an emerging story. Trends Plant Sci 14: 399-408.

Philippar K, Fuchs I, Luthen H, Hoth S, Bauer CS, Haga K, Thiel G, Ljung K, Sandberg G, Bottger M, et al. 1999. Auxin-induced $\mathrm{K}+$ channel expression represents an essential step in coleoptile growth and gravitropism Proc Natl Acad Sci 96: 12186-12191.

Philippar K, Ivashikina N, Ache P, Christian M, Luthen H, Palme K, Hedrich R. 2004. Auxin activates KAT1 and KAT2, two $\mathrm{K}+$-channel genes expressed in seedlings of Arabidopsis thaliana. Plant J 37: 815-827.

Porceddu A, Stals H, Reichheld JP, Segers G, De Veylder L, Barroco RP, Casteels P, Van Montagu M, Inze D, Mironov V. 2001. A plant-specific cyclin-dependent kinase is involved in the control of $\mathrm{G} 2 / \mathrm{M}$ progression in plants. J Biol Chem 276: 36354-36360.

Rayle DL, Cleland RE. 1992. The Acid Growth Theory of auxin-induced cell elongation is alive and well. Plant Physiol 99: 1271-1274.

Redig P, Shaul O, Inze D, Van Montagu M, Van Onckelen H. 1996. Levels of endogenous cytokinins, indole-3-acetic acid and abscisic acid during the cell cycle of synchronized tobacco BY-2 cells. FEBS Lett 391: 175-180.

Ren S, Johnston JS, Shippen DE, McKnight TD. 2004. TELOMERASE ACTIVATOR1 induces telomerase activity and potentiates responses to auxin in Arabidopsis. Plant Cell 16: 2910-2922.

Ren S, Mandadi KK, Boedeker AL, Rathore KS, McKnight TD. 2007. Regulation of telomerase in Arabidopsis by BT2, an apparent target of TELOMERASE ACTIVATOR1. Plant Cell 19: 23-31.

Richard C, Granier C, Inze D, De Veylder L. 2001. Analysis of cell division parameters and cell cycle gene expression during the cultivation of Arabidopsis thaliana cell suspensions. J Exp Bot 52: 1625-1633.

Rose JK, Braam J, Fry SC, Nishitani K. 2002. The XTH family of enzymes involved in xyloglucan endotransglucosylation and endohydrolysis: Current perspectives and a new unifying nomenclature. Plant Cell Physiol 43: 1421-1435.

Rück A, Pälme K, Venis MA, Napier RM, Felle RH. 1993. Patch-Clamp analysis establishes a role for an auxin binding protein in the auxin stimulation of plasma membrane current in Zea-Mays protoplasts. Plant Journal 4: 41-46.

Sampedro J, Cosgrove DJ. 2005. The expansin superfamily. Genome Biol 6: 242.

Schnittger A, Schobinger U, Bouyer D, Weinl C, Stierhof YD, Hulskamp M. 2002. Ectopic D-type cyclin expression induces not only DNA replication but also cell division in Arabidopsis trichomes. Proc Natl Acad Sci 99: 64106415.

Shimomura S. 2006. Identification of a glycosylphosphatidylinositol-anchored plasma membrane protein interacting with the $\mathrm{C}$-terminus of auxin-binding protein 1 : A photoaffinity crosslinking study. Plant Mol Biol 60: 663-677.

Sorrell DA, Menges M, Healy JM, Deveaux Y, Amano C, Su Y, Nakagami H, Shinmyo A, Doonan JH, Sekine M, et al. 2001. Cell cycle regulation of cyclin-dependent kinases in tobacco cultivar Bright Yellow-2 cells. Plant Physiol 126: 1214-1223.

Stals H, Inze D. 2001. When plant cells decide to divide. Trends Plant Sci 6: 359-364.

Steffens B, Feckler C, Palme K, Christian M, Bottger M, Luthen H. 2001. The auxin signal for protoplast swelling is perceived by extracellular ABP1. Plant J 27: 591-599.

Swarup K, Benkova E, Swarup R, Casimiro I, Peret B, Yang Y, Parry G, Nielsen E, De Smet I, Vanneste S, et al. 2008. The auxin influx carrier LAX3 promotes lateral root emergence. Nat Cell Biol 10: 946-954.

Takesue K, Shibaoka H. 1998. The cyclic reorientation of cortical microtubules in epidermal cells of azuki bean epicotyls: The role of actin filaments in the progression of the cycle. Planta 205: 539-546.

Takesue K, Shibaoka H. 1999. Auxin-induced longitudinalto-transverse reorientation of cortical microtubules in nonelongating epidermal cells of azuki bean epicotyls. Protoplasma 206: 27-30.

Tamura K, Liu H, Takahashi H. 1999. Auxin induction of cell cycle regulated activity of tobacco telomerase. J Biol Chem 274: 20997-21002.

Thiel G, Weise R. 1999. Auxin augments conductance of K+ inward rectifier in maize coleoptile protoplasts. Planta 208: $38-45$.

Thiel G, Blatt MR, Fricker MD, White IR, Millner P. 1993. Modulation of $\mathrm{K}+$ channels in Vicia stomatal guard cells by peptide homologs to the auxin-binding protein $\mathrm{C}$ terminus. Proc Natl Acad Sci 90: 11493-11497.

Timpte C. 2001. Auxin binding protin: Curiouser and curiouser. Trends in Plant Science.

Trehin C, Planchais S, Glab N, Perennes C, Tregear J, Bergounioux C. 1998. Cell cycle regulation by plant growth regulators: Involvement of auxin and cytokinin in the re-entry of Petunia protoplasts into the cell cycle. Planta 206: $215-224$.

Trewavas AJ, Cleland RE. 1983. Is plant development regulated by changes in the concentration of growth substances or by changes in the sensitivity to growth substances? Trends Biochem Sci 8: 354-357.

Tromas A, Braun N, Muller P, Khodus T, Paponov IA, Palme K, Ljung K, Lee JY, Benfey P, Murray JA, et al. 2009. The AUXIN BINDING PROTEIN 1 is required for differential 
auxin responses mediating root growth. PLoS One 4: e6648.

Vandepoele K, Raes J, De Veylder L, Rouze P, Rombauts S, Inze D. 2002. Genome-wide analysis of core cell cycle genes in Arabidopsis. Plant Cell 14: 903-916.

Waller F, Riemann M, Nick P. 2002. A role for actin-driven secretion in auxin-induced growth. Protoplasma 219: $72-81$.

Wasteneys GO, Galway ME. 2003. Remodeling the cytoskeleton for growth and form: an overview with some new views. Annu Rev Plant Biol 54: 691-722.

Wyatt SE, Carpita NC. 1993. The plant cytoskeleton-cellwall continuum. Trends Cell Biol 3: 413-417.

Xu J, Scheres B. 2005. Cell polarity: ROPing the ends together. Curr Opin Plant Biol 8: 613-618.
Yamagami M, Haga K, Napier RM, Iino M. 2004. Two distinct signaling pathways participate in auxin-induced swelling of pea epidermal protoplasts. Plant Physiol 134: $735-747$.

Yang Z, Fu Y. 2007. ROP/RAC GTPase signaling. Curr Opin Plant Biol 10: 490-494.

Yokoyama R, Nishitani K. 2001. A comprehensive expression analysis of all members of a gene family encoding cell-wall enzymes allowed us to predict cis-regulatory regions involved in cell-wall construction in specific organs of Arabidopsis. Plant Cell Physiol 42: 1025-1033.

Zhang K, Letham DS, John PC. 1996. Cytokinin controls the cell cycle at mitosis by stimulating the tyrosine dephosphorylation and activation of p34cdc2-like $\mathrm{H} 1$ histone kinase. Planta 200: 2-12. 


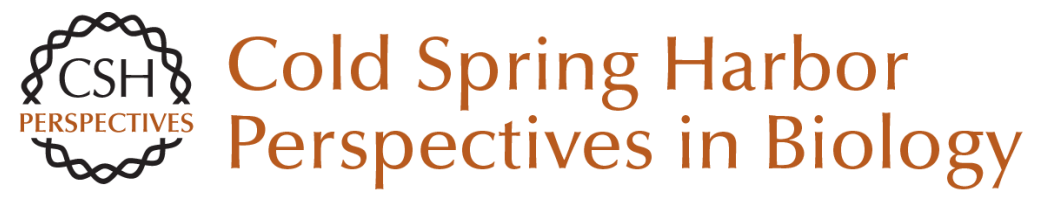

\section{Cellular Responses to Auxin: Division versus Expansion}

Catherine Perrot-Rechenmann

Cold Spring Harb Perspect Biol 2010; doi: 10.1101/cshperspect.a001446 originally published online April 7, 2010

\section{Subject Collection Auxin Signaling}

Fourteen Stations of Auxin Jirí Friml

Computational Models of Auxin-Driven Patterning in Shoots

Mikolaj Cieslak, Andrew Owens and Przemyslaw Prusinkiewicz

Auxin Transporters--A Biochemical View Ulrich Z. Hammes, Angus S. Murphy and Claus Schwechheimer

Structural Aspects of Auxin Signaling Nicholas Morffy and Lucia C. Strader

The Story of Auxin-Binding Protein 1 (ABP1) Richard Napier

Noncanonical Auxin Signaling Heather Marie McLaughlin, Aaron Chun Hou Ang and Lars Østergaard

Casting the Net--Connecting Auxin Signaling to the Plant Genome Yanfei Ma, Sebastian Wolf and Jan U. Lohmann

Auxin Plays Multiple Roles during Plant-Pathogen Interactions

Barbara N. Kunkel and Joshua M.B. Johnson
Auxin in Root Development

Suruchi Roychoudhry and Stefan Kepinski

Modeling Auxin Signaling in Roots: Auxin Computations

Jaap Rutten, Thea van den Berg and Kirsten ten Tusscher

The Systems and Synthetic Biology of Auxin $R$. Clay Wright, Britney L. Moss and Jennifer $L$. Nemhauser

Auxin Does the SAMba: Auxin Signaling in the

Shoot Apical Meristem Markéta Pernisová and Teva Vernoux

Chemical Biology in Auxin Research Ken-ichiro Hayashi

Uncovering How Auxin Optimizes Root Systems Architecture in Response to Environmental Stresses Nicola Leftley, Jason Banda, Bipin Pandey, et al.

Auxin Interactions with Other Hormones in Plant Development

Serina M. Mazzoni-Putman, Javier Brumos, Chengsong Zhao, et al.

No Time for Transcription--Rapid Auxin

Responses in Plants

Shiv Mani Dubey, Nelson B.C. Serre, Denisa Oulehlová, et al.

For additional articles in this collection, see http://cshperspectives.cshlp.org/cgi/collection/

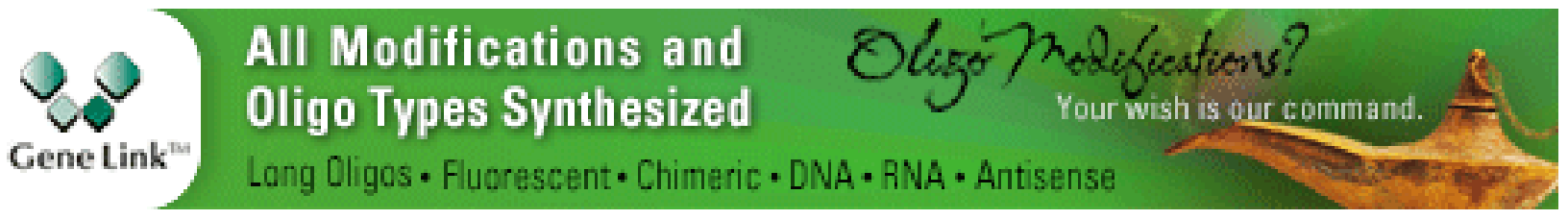


For additional articles in this collection, see http://cshperspectives.cshlp.org/cgi/collection/

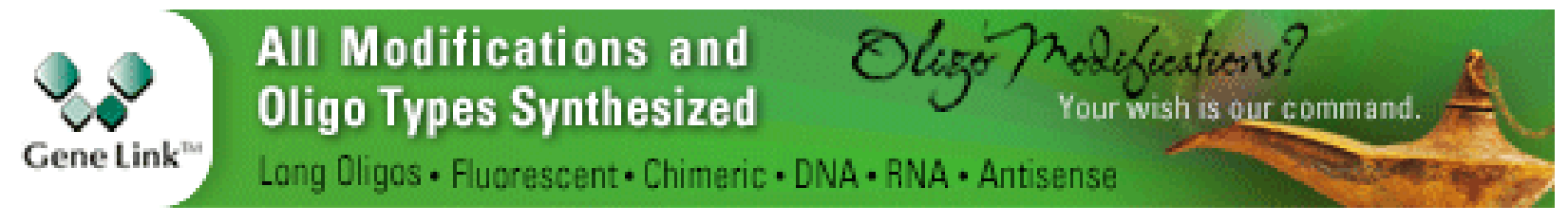

Copyright @ 2010 Cold Spring Harbor Laboratory Press; all rights reserved 